\title{
Numerical analysis and verification of residual stress in $T$ joint of S355 steel
}

\author{
Wang Xiangming, Guo Erfu \\ School of Mechanical and Electrical Engineering, Shijiazbuang University of Applied Technology, Shijiazhuang, 050081 \\ wangxmxming@163.com
}

\begin{abstract}
T joint is a widely used welding form. The welding deformation and residual stress produced during the welding process affect the integrity and reliability of the resultant structure. In this study, S355 low alloy steel was used as test material, and the thermal-mechanical coupling characteristics of multi-layer welding were combined with SYSWELD finite element software to calculate the residual welding stress of $\mathrm{T}$ joint. The residual welding stress of multi-layer welding $\mathrm{T}$ joint with tangent tube and sheet was measured using $\mathrm{X}$-ray diffraction method. The results showed that the numerical simulation was in good agreement with the experimental findings. With respect to the transverse residual stress, the maximum residual stress appeared near the weld toe. The transverse stress perpendicular to the weld direction represented the tensile stress at the weld center as well as the tensile stress at the tube surface far from the weld. Regarding longitudinal residual stress, the maximum residual stress also appeared near the weld toe, and its value was highest at the center of the weld, but decreased along the direction perpendicular to the weld. These results can serve as useful guide for actual welding design.
\end{abstract}

KEYWORDS. T joint; Residual stress; Welding deformation; Finite element method.

\section{open Access}

Citation: Wang, XM., Guo, EF., Numerical Analysis and Verification of Residual Stress in T Joint of S355 Steel, Frattura ed Integrità Strutturale, 52 (2020) 25-32.

Received: 04.08 .2020

Accepted: 21.04.2020

Published: 01.04.2020

Copyright: (C) 2020 This is an open access article under the terms of the CC-BY 4.0, which permits unrestricted use, distribution, and reproduction in any medium, provided the original author and source are credited.

\section{INTRODUCTION}

$\mathrm{T}$ he main connection mode in steel structure engineering in China is welding connection. This connection method is economical and flexible: it simplifies the structural details, saves materials and improves production efficiency [1]. Welding connection has been widely used in ship, locomotive, vehicle, bridge, boiler and other industrial fields, and also in energy engineering, marine engineering, aerospace engineering, petrochemical engineering, large plants and high-rise buildings [2-5].

$\mathrm{T}$ joint is a common joint in welding. Residual stress and welding deformation are important factors that affect the accuracy and performance of welding products [6,7]. Welding deformation and residual stress affect mechanical properties such as resistance to corrosion and crack growth, and fatigue strength [8,9]. Moreover, they have tremendous impact on the physical and mechanical properties of materials. T joint is one of main structures of bogie beam components, and its welding residual stress affects the load-carrying capacity, fatigue strength, structural stiffness and dimensional precision of bogie beam. In recent years, a large number of scholars in China and elsewhere have studied the prediction and control of post-weld deformation and residual stress. Wudi et al. [10] tested the residual stress in Q345 steel welded with MAG, and compared 
and analyzed the residual stress in the fusion zone and heat affected zone. In another study, Mato Peridic et al. [11] simulated and tested the residual welding stress and defects in $\mathrm{T}$ joint, and proved that the peak value of residual stress appeared near the weld toe. Inoue et al. [12] studied the effect of coupling of temperature, phase transition and thermal stress in the process of temperature change accompanying phase transition, and proposed a general form of constitutive equation under the coupling condition. However, reports on the welding simulation of $\mathrm{T}$ joint of S355 steel are scanty.

Based on the finite element numerical simulation method, the residual stress of $\mathrm{T}$ joint of steel S355 after wielding was calculated as a function of the thermo-mechanical coupling characteristics of multi-layer welding. Then the residual stress of $\mathrm{T}$ joint with tangent tube and sheet was measured with X-ray diffraction test. The transient stress changes and the distribution of residual stresses during welding were simulated. The results of the numerical simulation laid a foundation for the subsequent optimization of welding process parameters and the realization of residual stress control based on numerical simulation.

\section{ESTABLISHMENT OF FINITE ELEMENT MODEL}

\section{Establishment of Finite Element Mesh Model}

7 inite element meshing was accomplished with Hypermesh software. The total number of meshes was 488910, with 452741 nodes. The maximum mesh element size was $5 \mathrm{~mm} \times 3 \mathrm{~mm} \times 0.8 \mathrm{~mm}$, while the minimum mesh element size was $5 \mathrm{~mm} \times 1 \mathrm{~mm} \times 0.8 \mathrm{~mm}$ (Fig. 1 and 2). In order to ensure the convergence of the calculation results, the base grids of the weld and immediate vicinity of the weld were divided tightly in the mesh generation process, while the mesh far from the weld was sparsely divided [10].

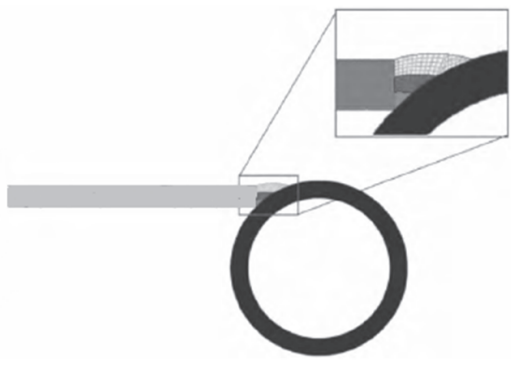

Figure 1: Network model.

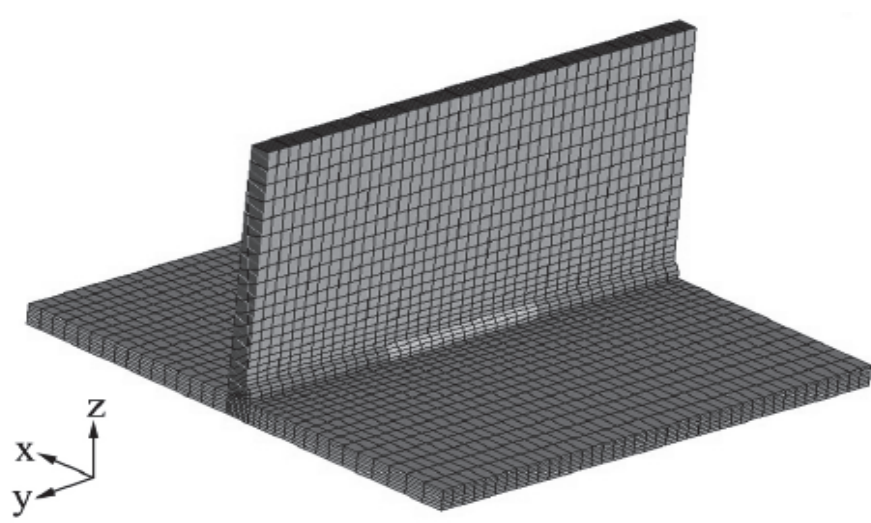

Figure 2: The finite element model of $\mathrm{T}$ joint.

At the end of mesh partitioning, Visual-Mesh was imported for grouping, and constraints were imposed. The constraints are shown in Fig. 3, i.e., exerting clamping on the node along the axes pointed by the arrow to ensure arrest of the rigid motion.

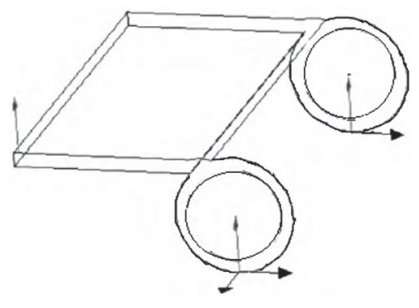

Figure 3: Constraints.

\section{Establishment of Material Model}

Considering the effect of phase change on residual stress and deformation during welding, the main phases of materials such as ferrite, pearlite and martensite were loaded in the simulation process. Their thermophysical properties are shown in Fig. 4. 


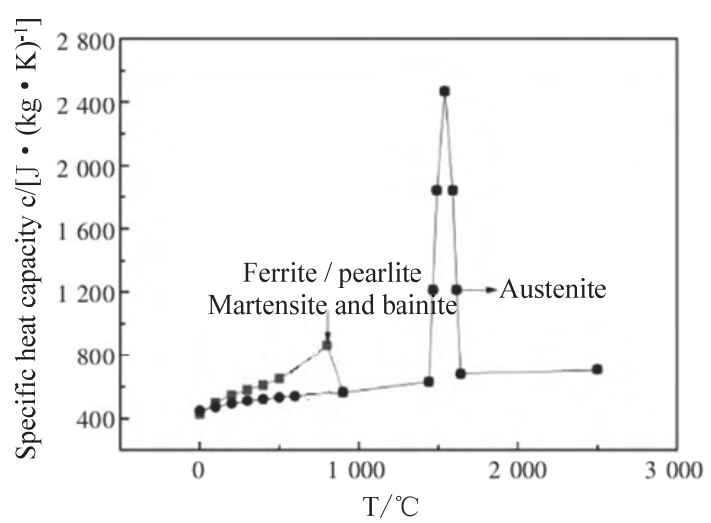

(a) Specific heat capacity

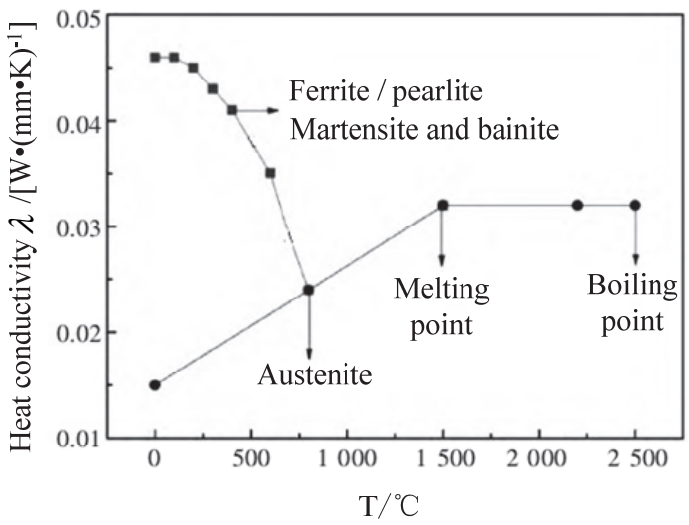

(b) Thermal conductivity

Figure 4: Thermophysical properties of S355 material.

\section{Double Ellipsoid Heat Source Model}

The double ellipsoid heat source model was used as the heat source for deformation simulation. Double ellipsoid heat source is a kind of volume-distributed heat source [14]. Its heat source model shows three-dimensional distribution in space. It considers not only the plane distribution of heat flow on the action surface, but also the distribution of heat energy along the direction of thickness of the plate. At present, the double ellipsoidal heat source model proposed by Goldak is effective since it takes full account of the asynchronism of the temperature changes at the front and back ends of the heat source in the welding process. Moreover, it provides a more accurate description of heat source than the hemispherical and ellipsoidal heat sources. The double ellipsoid heat source model is shown in Fig. 5.

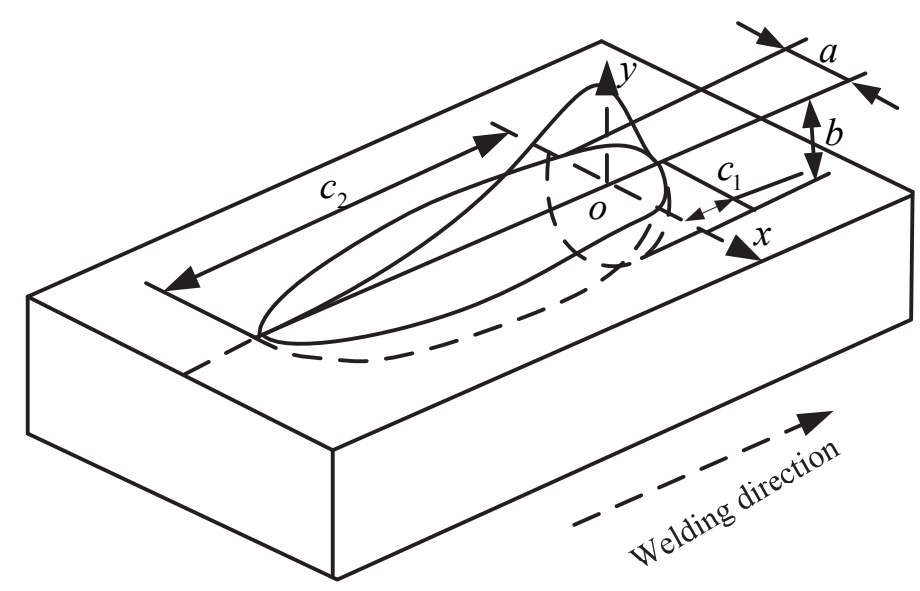

Figure 5: Double ellipsoid heat source model.

Different expressions are used for the front and back parts of the double ellipsoid heat source model. The expression for the heat source distribution in the front part of the ellipsoid is:

$$
q(x, y, z)=\frac{6 \sqrt{3} f_{1} Q}{\pi \mathrm{a}_{1} b c \sqrt{\pi}} \exp \left(-3 \frac{x^{2}}{a_{2}^{2}}\right) \exp \left(-3 \frac{y^{2}}{b^{2}}\right) \exp \left(-3 \frac{z^{2}}{c^{2}}\right)
$$

The expression of the heat source distribution in the back part of the ellipsoid is: 


$$
q(x, y, z)=\frac{6 \sqrt{3} f_{2} Q}{\pi \mathrm{a}_{2} b c \sqrt{\pi}} \exp \left(-3 \frac{x^{2}}{a_{2}^{2}}\right) \exp \left(-3 \frac{y^{2}}{b^{2}}\right) \exp \left(-3 \frac{z^{2}}{c^{2}}\right)
$$

where $\mathrm{Q}=\eta \mathrm{UI}$ ( $\eta$ is heat source efficiency), $\mathrm{U}$ is arc voltage, $\mathrm{V}, \mathrm{I}$ is welding current, $\mathrm{A}$; a, b and c are ellipsoidal parameters, and $f_{1}$ and $f_{2}$ are the heat distribution functions of the front and back parts of the ellipsoid, $f_{1}+f_{2}=2$.

In order to obtain an accurate heat source model, it was necessary to check its heat source. Firstly, the initial values of the heat source parameters of the double ellipsoid heat source model were given, and the calculated results were compared with the actual weld pool shape. Constant adjustment made the simulation results consistent with the shape of weld pool, and the correct heat source model was obtained. Finally, the parameters obtained were: $a_{1}=2.5, a_{2}=5, b=2, c=3$. SYSWELD software provides the solution method of average thermal cycle curve. Fig. 6 shows the average thermal cycle curve obtained using SYSWELD software.

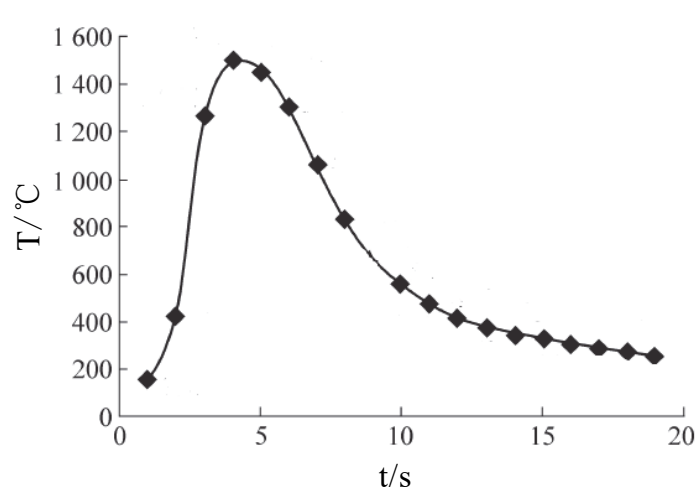

Figure 6: Average thermal cycle curve of welding.

\section{CALCULATION OF RESIDUAL STRESS}

ulti-layer welding was used in the welding process. The welding sequence is shown in Fig. 7. The heat input was $0.74,1.05$ and $1.48 \mathrm{~J} / \mathrm{mm}$, respectively. The welding process was simulated based on SYSWELD and the coupling characteristics of multi-layer welding.

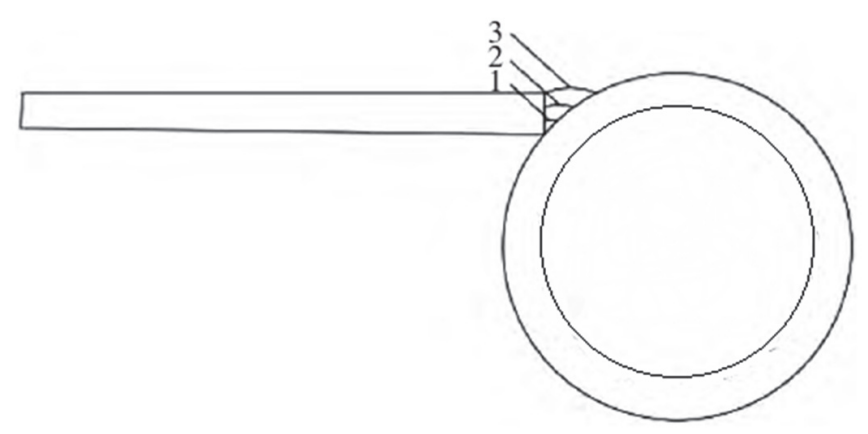

Figure 7: Welding sequence.

After the welding simulation process of heating, cooling and stress annealing, the transverse and longitudinal stress distribution nephograms were obtained (Fig. 8).

It can be seen intuitively from Fig. 8 that the post-weld peak values of transverse and longitudinal residual stresses appeared at the re-striking arc on the surface of the weld center. This phenomenon was due to the fact that an unstable arc at the superimposed arc could lead to decrease in the fusion ratio between the filler material and the base metal of the previous weld [15], thereby resulting in the concentration of residual stress at the re-striking arc of the weld. Moreover, it is clearly shown in Fig. 8 that the longitudinal ( $z$ direction) peak residual stress and the transverse ( $x$ direction) peak residual stress 
appeared at the weld. When the welding pool was melting the base metal and filler material, the surrounding non-melting low-temperature base metal produced compressive stress and compressive plastic deformation due to temperature difference, while the metal of the weld produced tensile residual stress under the tensile action of the surrounding base metal during cooling. However, the tensile plastic stress induced by the tensile residual stress was unable to offset the compressive plastic stress produced previously. Thus, to balance the residual thermal plastic strain at the weld during cooling, large tensile stress occurred at the weld. That was why the longitudinal peak residual stress and the transverse peak residual stress appeared at the weld. Moreover, in order to balance the tensile stress of the system at the weld on both sides of the base metal, compressive stress was displayed on both sides far from the center of the weld. The compressive stress prevented large bending deformation of the specimens and maintained the overall stress balance in the specimens.

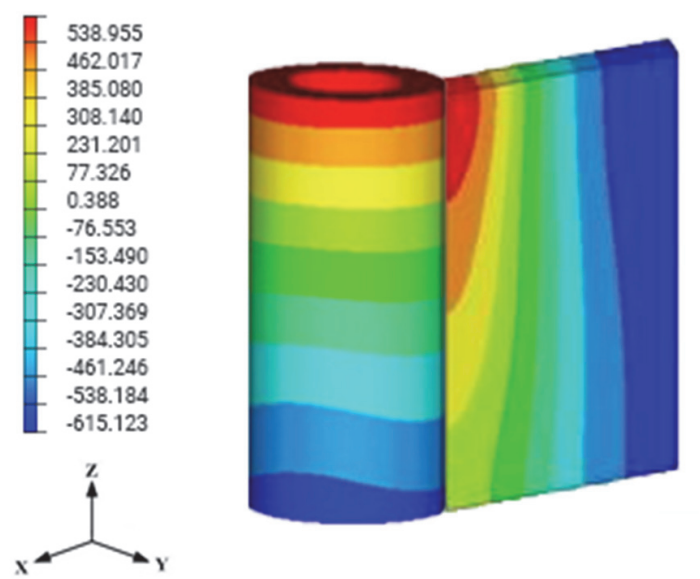

(a) Nephogram of transverse residual stress distribution
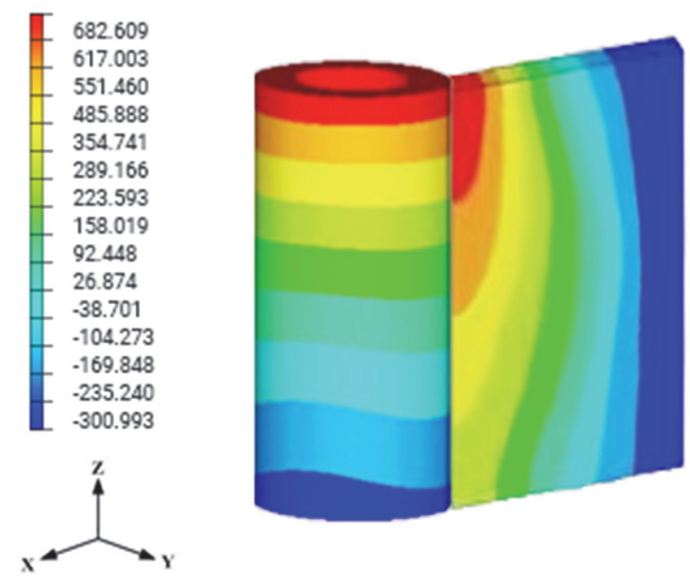

(b) Nephogram of longitudinal residual stress distribution

Figure 8: Residual stress distribution nephogram

It can be seen intuitively from Fig. 8 that the post-weld peak values of transverse and longitudinal residual stresses appeared at the re-striking arc on the surface of the weld center. This phenomenon was due to the fact that an unstable arc at the superimposed arc could lead to decrease in the fusion ratio between the filler material and the base metal of the previous weld [15], thereby resulting in the concentration of residual stress at the re-striking arc of the weld. Moreover, it is clearly shown in Fig. 8 that the longitudinal ( $\mathrm{z}$ direction) peak residual stress and the transverse (x direction) peak residual stress appeared at the weld. When the welding pool was melting the base metal and filler material, the surrounding non-melting low-temperature base metal produced compressive stress and compressive plastic deformation due to temperature difference, while the metal of the weld produced tensile residual stress under the tensile action of the surrounding base metal during cooling. However, the tensile plastic stress induced by the tensile residual stress was unable to offset the compressive plastic stress produced previously. Thus, to balance the residual thermal plastic strain at the weld during cooling, large tensile stress occurred at the weld. That was why the longitudinal peak residual stress and the transverse peak residual stress appeared at the weld. Moreover, in order to balance the tensile stress of the system at the weld on both sides of the base metal, compressive stress was displayed on both sides far from the center of the weld. The compressive stress prevented large bending deformation of the specimens and maintained the overall stress balance in the specimens.

\section{MEASUREMENT AND COMPARATIVE ANALYSIS OF RESIDUAL STRESS}

\section{Measurement of Residual Stress using X-ray}

$\checkmark$ he test specimen was a $T$ joint with tube and sheet in tangential orientation. The size of the test sheet was $350 \mathrm{~mm}$ $\times 150 \mathrm{~mm} \times 12 \mathrm{~mm}$, and the tube was circular, with an inner diameter of $80 \mathrm{~mm}$, a 100-mm outer diameter and a length of $350 \mathrm{~mm}$. The test followed GB/T 2008-7704 Standard for X-ray Non-destructive Stress Detection. The testing instrument used was I XRD X-ray diffraction stress meter, and $\mathrm{Cr}$ target was the target material. The residual stresses of the center of the weld and the sites were 2, 5,12,15 and $25 \mathrm{~mm}$ away from the surface of the weld toe tested. The testing position is shown in Fig. 9. 


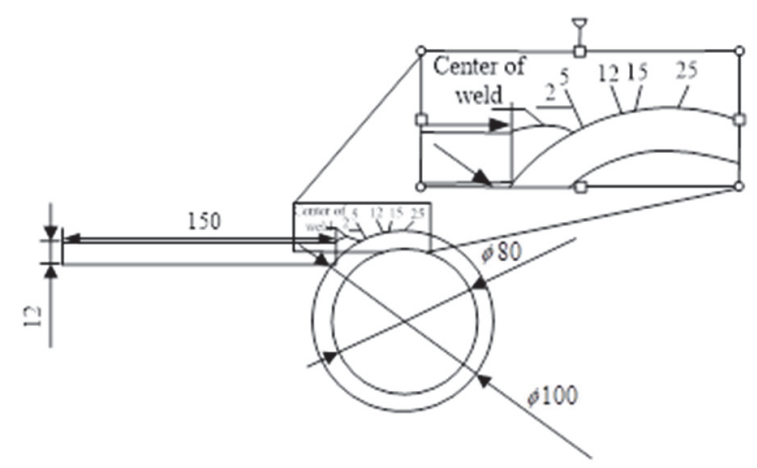

Figure 9: The testing position of the residual stress of the weld.

\section{Comparison and Analysis of Simulation Results and Experimental Results}

With reference to the test range, the longitudinal and transverse residual stresses of the weld were extracted from the simulation results. The residual stress obtained in the test and simulations were compared, and the residual stress curve was drawn, as shown in Fig. 10.

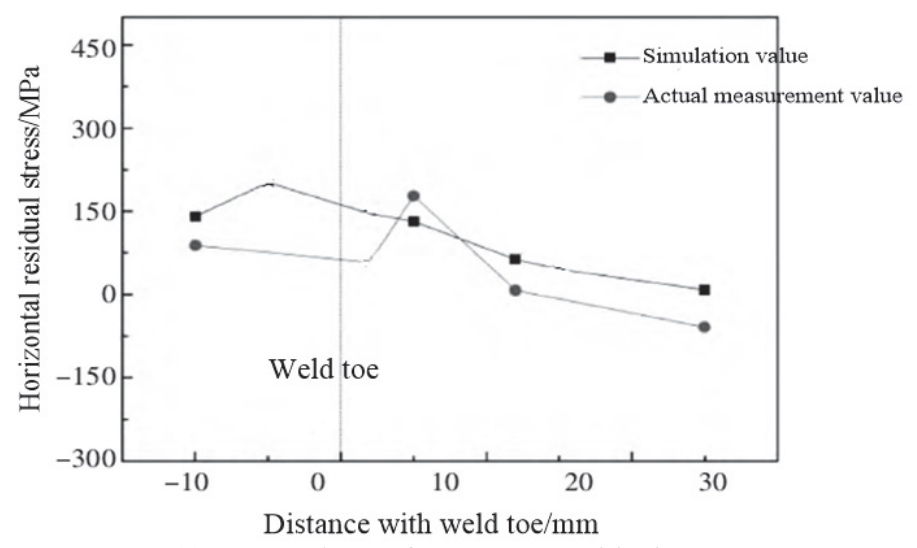

(a) Comparison of transverse residual stress.

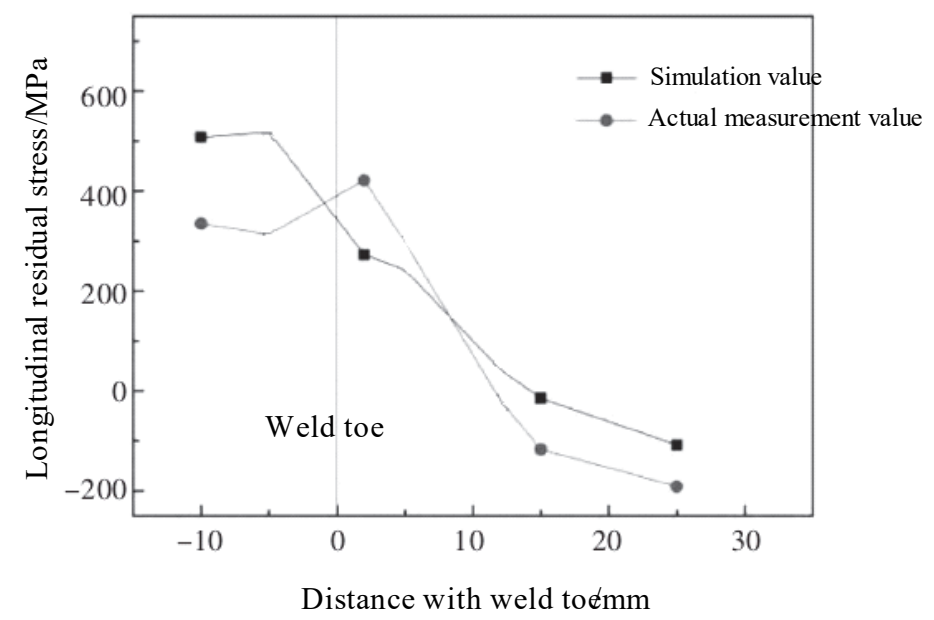

(b) Comparison of longitudinal residual stress

Figure 10: Comparison of measured and simulated residual stress

Fig. 10 shows clearly that the trends in variation in the transverse residual stress and longitudinal residual stress were quite close, and the maximum residual stress also appeared near the weld toe. Moreover, it could be seen from the trend of the whole curve that the residual stress at the weld was very large, showing a state of tensile stress, and the tube surface far from 
the weld showed a state of compressive stress as a function of distance. With respect to longitudinal residual stress, the tensile stress was applied at the center of the weld, and the compressive stress appeared when it moved away from the center of the weld to both sides $[16,17]$.

Fig. 10a is a comparison of transverse residual stresses. It could be seen clearly from the figure that the maximum simulation value of $203 \mathrm{MPa}$ appeared at the weld which was $5 \mathrm{~mm}$ away from the weld toe. The maximum measured value (179 MPa) appeared at the tube surface side which was $5 \mathrm{~mm}$ away from the weld toe. The difference between the two peak values was $24 \mathrm{MPa}$, suggesting high coincidence. Fig. 10b shows comparison of longitudinal residual stresses. It can be seen from the figure that the maximum simulation value of $517 \mathrm{MPa}$ appeared at the weld $5 \mathrm{~mm}$ away from the weld toe, while the maximum measured value of $422 \mathrm{MPa}$ appeared at the tube surface which was $2 \mathrm{~mm}$ away from the weld toe. The difference between the two peak values was $95 \mathrm{MPa}$, again suggesting high coincidence.

It should be pointed out that the center of the weld experienced two thermal cycle processes, since the welding was continuous, thereby avoiding the problem of re-striking arc, and every layer was calculated in two sections in the simulation process. Therefore, the simulated peak values of both transverse and longitudinal residual stresses were slightly higher than the experimental peak values.

\section{CONCLUSIONS}

hrough the numerical simulation calculation and analysis of SYSWELD, changes in transient stress and the distribution of post-weld residual stress were analyzed in detail. The concrete conclusions are as follows:

(1) The maximum residual stress of multi-layer welding of S355 low-alloy steel appeared on the surface of the weld, indicating that the current weld was obtained after performing post-weld thermal treatment on the last weld. Therefore, the residual welding stress of the last weld was greatly reduced. However, the last weld, i.e. the weld surface in the test, did not experience the effect of post-weld heat treatment. Thus, the residual stress was relatively prominent. Therefore, the residual stress on the surface of the weld was largest, followed by residual stress at the middle of the weld, and residual stress at the weld.

(2) For T joint with tangent sheet and tube, the curves of simulation and test values were similar, with small difference in peak stress. The transverse residual stress perpendicular to the weld surface along one tube side showed tensile stress at the center of the weld, while the transverse residual stress far from the weld center showed compressive stress. The longitudinal residual stress also showed peak tensile stress at the weld center, and there was tensile stress when it moved towards the tube surface.

In addition, it is important to point out that the simulated longitudinal peak residual stress was $538 \mathrm{MPa}$ and the test longitudinal peak residual stress was $421 \mathrm{MPa}$. These values exceeded the yield limit of S355 low alloy steel (355 MPa), which would affect the fatigue life of the weldment to some extent. Therefore, in the actual welding process in the future, special attention should be paid to the control of inter-channel temperature and welding speed to prevent excessive peak residual stress after welding caused by excessive heat input.

\section{REFERENCES}

[1] Chen, L.M. (2012). The influence of temperature control in welding process on the qualification rate of welded parts, China Packaging Industry, (13), pp. 43.

[2] Alyakrinskiy, O.N., Logachev, P.V. and Semenov, Y.I. (2017). Investigation of the process of electronic beam welding in an external magnetic field, Welding International, 31(8), pp. 1-4.

[3] Hu, W.H., Wang, G.Y. and Yang, X.H. (2018). Study on the residual stress of truck frame welding of high speed train, Welding Technology, 47(3), pp. 19-22.

[4] Cong, S., Zhang, W.W., Wang, Y.S., Wen, Z.J. and Tian, Y.H. (2018). Effect of heat input on failure mode and connection mechanism of parallel micro-gap resistance welding for copper wire, International Journal of Advanced Manufacturing Technology, 96(1), pp. 299-306.

[5] Jin, S.W., Ohmori, H. and Lee, S.J. (2017). Optimal design of steel structures considering welding cost and constructability of beam-column connections, Journal of Constructional Steel Research, 135(673), pp. $292-301$.

[6] Shanmugam, N.S., Buvanashekaran, G., Sankaranarayanasamy, K. and Kumar, S.R. (2010). A transient finite element simulation of the temperature and bead profiles of T-joint laser welds, International Journal of Modelling \& Simulation, 30(1), pp. 108-122. 
[7] Huang, J., Liu, Y.G., Zhang, T. and Xie, F. (2009). Experimental study on residual stress of thick plate welding, Chinese Ship Research, 4(5), pp. 33-37.

[8] Jia, K.N., Wang, H.D. and Jiang, Q.Y. (2012). Study on welded cold cracking susceptibility of high-strength bridge steel, Electric Welding Machine, 42(2), pp. 23-25.

[9] Katsuyama, J., Tobita, T., Itoh, H. and Onizawa, K. (2012). Effect of welding conditions on residual stress and stress corrosion cracking behavior at butt-welding joints of stainless steel pipes, Journal of Pressure Vessel Technology, 134(2), pp. 021403. DOI: $10.1115 / 1.4005391$

[10] Wu, D., Zhang, C., Zhu, H.R. and Han, S. (2016). Weld residual stress test for welded Q345 steel, Construction Machinery, (11), pp. 86-88.

[11] Peric, M., Tonkovic, Z., Rodic, A., Surjak, M., Garasic, I. and Boras, I. (2014). Numerical analysis and experimental investigation of welding residual stresses and distortions in a T-joint fillet weld, Materials \& Design, 53(1), pp. 10521063.

[12] Inoue, T. (1996). Metllo-Thermo-Mechanics application to phase transformation incorporated processes, Trans. JWRI, 25(2), pp. 69-87.

[13] Feng, X.N., Liu, Y.L., Yang, X.H. and He, X.L. (2017). Numerical simulation and test of multi-layer multi-weld residuall stress of Q345E steel, Welding Technology, 46(11), pp. 5-9.

[14] Du, B.S., Ma, X.Z., Zhang, Z.W. and Xu, G.X. (2014). Numerical simulation of residual stress in multipass weld joint of ultrafine-grained Q460 steel, Transactions of The China Welding Institution, 35(2), pp. 42-46.

[15] Zhang, G.D. and Zhou, C.Y. (2006). Finite element analysis of pipe discontinuous and continuous butt welding, Transactions of The China Welding Institution, 27(12), pp. 85-88.

[16] Li, Z.Z., Zhou, J.P., Xu, Y. and Li, B.R. (2016). Numerical simulation analysis on T-shaped pipe weldments temperature and stress-strain field based on SYSWELD, Transactions of The China Welding Institution, 37(4), pp. 77.

[17]Jiang, K.B., Xiao, Y.T. and Guo, Y.T. (2008). Determination of welding residual stress distribution of T-type welding samples, Journal of Welding, 29(1), pp. 53-56. 